\title{
Erratum
}

\section{A Framework for Defining the Generality of Diophantos' Methods in "Arithmetica"}

\author{
YANNIS THOMAIDIS \\ Communicated by B. VITRAC
}

\begin{abstract}
Unfortunately, footnote 48 was published with an error. The correct version is given here.

${ }^{48}$ In the course of the lengthy solution of problem "IV" 39, Diophantos employs the equality produced by the last step in the above "completion of square", for solving the inequality $6 x+18<2 x^{2}$. Making an explicit reference to the corresponding equation ("hotan toiautên isôsin isôsômen") he computes the number $2.18+(6 / 2)^{2}=45$, which is equal to $(2 x-6 / 2)^{2}$. Taking (positive) roots on both sides of $(2 x-3)^{2} \geq 49$ leads to the inequality $2 x-3 \geq 7$ from which follows that $\mathrm{x} \geq 5$.
\end{abstract}

Erratum published online September 2, 2005 - () Springer-Verlag 2005

The online version of the original article can be found at http://dx.doi.org/10.1007/s00407-005-0099-8 